\title{
GERMINAÇÃO E VIGOR DE SEMENTES DE ARROZ INOCULADAS COM BACTÉRIAS DIAZOTRÓFICAS
}

\author{
Rice seed germination and vigour as affected by the inoculation \\ with diazotrophic bacteria
}

\author{
Antonio Edilson da Silva Araújo ${ }^{1}$, Claudia Antonia Vieira Rossetto², \\ Vera Lúcia Divan Baldani ${ }^{3}$, José Ivo Baldani ${ }^{3}$
}

\begin{abstract}
RESUMO
Objetivou-se, neste trabalho, avaliar a germinação e o vigor das sementes de arroz inoculadas com bactérias diazotróficas. Foram instalados dois experimentos, sendo que no primeiro o delineamento experimental adotado foi o inteiramente casualizado em esquema fatorial, com dois lotes de sementes arroz da cultivar IC4440 x 10 tratamentos, com quatro repetições. Os tratamentos foram representados pela inoculação com oito estirpes de bactérias diazotróficas (AR1122, M130, BF1358, ZAE94, AR3122, AR2112, CD e BR2113), bem como pelo recobrimento das sementes com a turfa umedecida com o meio de cultivo esterilizado e pelas sementes não inoculadas. No segundo experimento, o delineamento experimental adotado foi o inteiramente casualizado, em esquema fatorial, com dois lotes de sementes recém-colhidas das cultivares IR42 e Zebu Branco x oito tratamentos, com quatro repetições. Os tratamentos foram representados pela inoculação das sementes com seis estirpes de bactérias diazotróficas (BF1358, AR3122, AR1122, ZAE94, M130 e AR2112), bem como pelo recobrimento das sementes com a turfa umedecida com o meio de cultivo esterilizado e pela não realização do procedimento de inoculação. As bactérias AR1122, M130, BF1358, ZAE94 e AR3112 podem ser selecionadas para formular inoculante para sementes de arroz. A inoculação com as bactérias diazotróficas aumenta a velocidade de germinação das sementes das cultivares IR42 e Zebu Branco, com menor contaminação por fungos.
\end{abstract}

Termos para indexação: Oryza sativa, inoculante, bioestimulante.

\begin{abstract}
The objective of this work was to evaluate the germination and vigour of rice seeds affected by inoculation with diazotrophic bacteria. Two experiments were conduced. In the first one, a completely randomized design with four replications arranged in a factorial scheme ( 2 lots x 10 treatments) was used. For this, rice seeds of cultivar IC4440 were inoculated with eight strains of diazotrophic (AR1122, M130, BF1358, ZAE94, AR3122, AR2112, CD e BR2113), submitted to coating with peat soil humidified with a sterile medium and not inoculated. In the second study, a completely randomized design with four replications arranged in a factorial scheme (2 lots x 6 treatments) was used. For this, recently harvested seeds of cultivars IR42 and Zebu Branco were inoculated with six strains (BF1358, AR3122, AR1122, ZAE94, M130 e AR2112), submitted to coating with peat soil humidified with a sterile medium and not inoculated. The bacteria AR1122, M130, BF1358, ZAE94 and AR3112 can be selected for inoculation of rice seeds. The inoculation of diazotrophic bacteria increases the speed of germination of rice seeds of cultivars IR42 e Zebu Branco, with low contamination by fungi.
\end{abstract}

Index terms: Oryza sativa, inoculant, bio-stimulator.

(Recebido em 19 de junho de 2008 e aprovado em 14 de julho de 2009)

\section{INTRODUÇÃO}

Um numeroso e diverso espectro de bactérias diazotróficas tem sido isolado de plantas de arroz (Elbeltagy et al., 2001; Muthukumarasamy et al., 2007). Segundo Peng et al. (2002) é possível que muitas dessas bactérias associadas às plantas de arroz estejam envolvidas na promoção do crescimento de plantas. A capacidade da população de microrganismos em promover o crescimento de plantas envolve mecanismos como a fixação biológica de nitrogênio, a produção de fito-hormônio e ou a solubilização de fosfato e o aumento na formação de pelos radiculares e, ou, a formação de raízes laterais, a inibição do crescimento de fungos e a indução de resistência sistêmica no hospedeiro (Rodriguez \& Fraga, 1999; Bevivino et al., 2005; Compent et al., 2005; Han et al., 2005). Atualmente, alguns estudos têm sido realizados no sentido de avaliar os aspectos benéficos da associação de bactérias diazotróficas com a germinação de sementes. Ramamoorthy et al. (2000) observaram aumento da germinação de sementes de arroz de dois lotes (com alto e baixo vigor) inoculadas com Azospirillum lipoferum e A. brasilense, após 14 dias de semeadura. Karthikeyan et al. (2007),

${ }^{1}$ Universidade Federal Rural do Rio de Janeiro/UFRRJ - Departamento de Fitotecnia - Seropédica, RJ

2Universidade Federal Rural do Rio de Janeiro/UFRRJ - Departamento de Fitotecnia - BR 465 - Km 7 - 23890-000 - Seropédica, RJ - cavrosse@ufrrj.br ${ }^{3}$ Embrapa Agrobiologia - Seropédica, RJ 
também observaram que a inoculação da semente de Catharanthus roseus (L.) com bactérias diazotróficas (Azospirillum e Azotobacter), isoladas da rizosfera e da raiz dessa planta, aumentou a porcentagem de germinação, assim como o vigor e o acúmulo de massa seca das plântulas crescidas em condições gnotobióticas. Na soja, observouse que a presença de Methylobacterium spp. estimulou a emissão de raiz primária das plântulas após cinco dias da instalação, devido a estimulo hormonal e quebra de dormência (Koenig et al., 2002). Diversos estudos têm indicado que a maioria das bactérias isoladas da rizosfera de plantas são produtoras de fito-hormônio (Barazani \& Friedman, 1999). Para Raven et al. (2001), fito-hormônio são essenciais na coordenação de diferentes aspectos da fisiologia de plantas, como germinação de sementes e formação de raízes, dentre outros. Arsego et al. (2006) observaram que o tratamento de sementes de arroz com giberelinas proporcionou o desenvolvimento de plântulas, com desempenho superior. De acordo com Farooq et al. (2006), plântulas vigorosas podem competir mais eficientemente, principalmente em condições de estresse por luz, nutrientes e água, influenciando no estabelecimento da população e na produção de grãos. Assim, a aplicação de bactérias diazotróficas com o objetivo de favorecer a germinação e o estabelecimento das plantas de arroz, pode ser uma tecnologia de baixo custo e de fácil adoção. Objetivou-se, neste trabalho, avaliar a germinação e o vigor de sementes de arroz, por meio da inoculação com bactérias diazotróficas.

\section{MATERIAL E MÉTODOS}

Foram conduzidos dois experimentos no Laboratório de Análise de sementes da UFRRJ, com sementes de arroz (Oryza sativa L.), no de ano 2007. No primeiro, o delineamento experimental adotado foi o inteiramente casualizado em esquema fatorial: dois lotes de sementes arroz da cultivar IC4440, armazenados em câmara regulada para $15{ }^{\circ} \mathrm{C}$ de temperatura e $50 \%$ de umidade relativa do ar por quatro (lote 1) e um ano (lote 2) x 10 tratamentos), com quatro repetições. Os tratamentos foram representados pela inoculação com oito estirpes de bactérias diazotróficas (Tabela 1), bem como pelo recobrimento das sementes com a turva umedecida com o meio de cultivo esterilizado (controle) e pelas sementes não inoculadas (testemunha). No segundo experimento, o delineanamento experimental adotado foi o inteiramente casualizado, em esquema fatorial (dois lotes de sementes recém-colhidas da área experimental da Embrapa Agrobiologia, no ano de 2007, em Seropédica/RJ.,das cultivares IR42 e Zebu Branco x oito tratamentos), com quatro repetições. Os tratamentos foram representados pela inoculação das sementes com seis estirpes de bactérias

Tabela 1 - Estirpes utilizadas nos tratamentos de inoculação.

\begin{tabular}{lll}
\hline & \multicolumn{2}{c}{ Experimento 1 } \\
\hline Bactérias & Estirpes & Referência \\
\hline Herbaspirillum & AR1122 & Araújo (2008) \\
Burkholderia brasilensis & M130 & Baldani (1996) \\
Azospirillum sp. & BF1358 & Araújo (2008) \\
H. seropedicae & ZAE94 & Baldani (1984) \\
Azospirillum amazonense & AR3122 & Araújo (2008) \\
Sphingomonas sp. & AR2112 & Araújo (2008) \\
A. brasilense & Cd & Tarrad et al. (1978) \\
A. brasilense & BR2113 & Araújo (2008) \\
\hline & & Experimento 2 \\
\hline Bactérias & Estirpes & Referência \\
\hline Azospirillum sp. & BF1358 & Araújo (2008) \\
Azospirillum amazonense & AR3122 & Araújo (2008) \\
Herbaspirillum & AR1122 & Araújo (2008) \\
H. seropedicae & ZAE94 & Baldani (1984) \\
Burkholderia brasilensis & M130 & Baldani (1996) \\
Sphingomonas sp. & AR2112 & Araújo (2008) \\
\hline
\end{tabular}


diazotróficas (Tabela 1), bem como pelo recobrimento das sementes com a turva umedecida com o meio de cultivo esterilizado (controle) e pela não realização do procedimento de inoculação (testemunha).

Para a preparação do inóculo para recobrimento, uma colônia do isolado de cada estirpe foi inoculada em meio DYGS (Rodrigues Neto et al., 1986), sob agitação. Após esse período, a concentração das células foi determinada por meio da densidade ótica em espectrofotômetro com comprimento de onda de $620 \mathrm{~nm}$ e foi ajustada para, aproximadamente, $10^{9}$ células $\mathrm{mL}^{-1}$. O inoculante foi preparado adicionando $15 \mathrm{~mL}$ da suspensão de cada bactéria em sacos de polietileno, contendo $35 \mathrm{~g}$ de turfa (previamente moída, seca, neutralizada acidez e esterilizada). Após o preparo, o inoculante foi mantido em estufa a $30^{\circ} \mathrm{C}$, por 24 horas. Em seguida, realizou-se a contagem das células em meio semisólido por meio da técnica do Número Mais Provável. O controle consistiu na adição de $15 \mathrm{~mL}$ do meio de cultivo esterilizado, em 35 $\mathrm{g}$ de turfa.

A inoculação das sementes foi realizada após a desinfestação superficial das sementes com hipoclorito de sódio a 1\%, por dez minutos (Chun et al., 1997) e, em seguida, essas foram lavadas, por quatro vezes em água destilada estéril e colocadas para secar em fluxo laminar, por duas horas. Essas sementes foram inoculadas, utilizado uma proporção de $10 \mathrm{~g}$ do inoculante por $\mathrm{kg}$ de semente, empregando uma solução de goma arábica a $10 \%$ para fixar o inoculante às sementes e, em seguida, colocadas para secar à sombra antes da utilização.

Foram realizadas as seguintes avaliações: teste de germinação e de vigor (primeira contagem de germinação e classificação das plântulas). O teste de germinação foi realizado seguindo as recomendações prescritas nas Regras para Análise de Sementes (Brasil, 1992). As sementes foram distribuídas em papel germitest previamente esterilizados e umedecidos com o volume de água 2,5 vezes a massa do substrato. Os rolos de papel com as sementes foram mantidos a $25^{\circ} \mathrm{C}$, sob 12 horas de luz. As avaliações foram realizadas aos cinco e aos 14 dias da instalação. Em conjunto com esse teste, foi realizado o teste de primeira contagem de germinação que constou na determinação da porcentagem de plântulas normais, verificadas no quinto dia após a instalação. Também em conjunto, foi realizado o teste de classificação de plântulas. As plântulas consideradas normais foram classificadas em fortes e fracas, sendo que as são fortes aquelas com maior desenvolvimento (provavelmente massa e comprimento) do coleóptilo e da raiz, bem como ausência de contaminação por fungos (Nakagawa, 1999). Os dados em porcentagem foram transformados em raiz quadrada do valor $+0.5 \mathrm{e}$ submetidos à análise de variância. A comparação entre médias foi feita por meio do teste de Tukey, a 5\% de probabilidade (Gomes, 1990).

No primeiro experimento, as bactérias que apresentaram maior capacidade antagonista contra o crescimento de Fusarium spp., gênero presente em maior quantidade nas sementes durante o teste de germinação, foram submetidas aos ensaios de inibição in vitro. Para isso, foi utilizado meio rico DYGS (Rodrigues Neto et al., 1986), colocando-se um disco de ágar de $0,5 \mathrm{~cm}$ de diâmetro com crescimento abundante do fungo a $1,5 \mathrm{~cm}$ da borda da placa e na outra extremidade uma estria da bactéria (Melo \& Valarine, 1995). O tratamento controle correspondeu á colocação do disco de ágar contendo o fungo em placa com o meio DYGS, não inoculado com bactérias diazotróficas. Após sete dias de incubação a $28^{\circ} \mathrm{C}$ e fotoperíodo de 12 horas, o crescimento micelial foi medido. $\mathrm{O}$ delineamento utilizado foi o inteiramente ao acaso, com quatro repetições. Os dados foram submetidos à análise de variância e, as médias, comparadas através do teste de Tukey, a $5 \%$ de probabilidade.

\section{RESULTADOS E DISCUSSÃO}

No primeiro experimento, houve interação dos tratamentos de inoculação (contendo no mínimo $10^{8}$ células por g) com os lotes de sementes de arroz colocados para germinar (Tabela 2). No lote de sementes, armazenado por quatro anos, houve aumento da germinação das sementes com a inoculação de bactérias AR1122, M130, BF1358 e ZAE94. Esse resultado provavelmente esteja relacionado à diminuição da porcentagem de plântulas anormais deterioradas, ou seja, contaminadas com fungos (Tabela 2).

Os resultados apresentados na Tabela 3 indicam que as bactérias BF1358, M130, AR1122 e ZAE94 foram capazes de inibir o desenvolvimento de fungo "in vitro". Han et al. (2005) relataram que bactérias diazotróficas associadas às gramíneas são importantes agentes no biocontrole de patógenos nessas plantas e Cavaglieri et al. (2005) observaram que bactérias do gênero Burkholderia são capazes de colonizar plantas de culturas importantes como milho, arroz e trigo, visando o controle contra Fusarium spp. Resultados semelhantes foram constatados em milho por Bevivino et al. (1998) e Bevivino et al. (2005) e, em banana por Weber et al. (2007). Além disso, segundo Kim et al. (1998) Sphingomonas são frequentemente encontradas em sementes de arroz e em outras partes dessa planta, podendo ser utilizadas para o controle de patógenos em arroz. 
Tabela 2 - Porcentagem de germinação e de plântulas anormais (deformadas e deterioradas) de doiss lotes de sementes de arroz da cv. IAC 4440 inoculadas com diferentes estirpes de bactérias diazotróficas.

\begin{tabular}{|c|c|c|c|c|c|c|c|c|c|}
\hline \multirow{2}{*}{ Estirpes } & \multicolumn{3}{|c|}{ Germinação } & \multicolumn{3}{|c|}{$\begin{array}{c}\text { Plântulas Anormais } \\
\text { Deformadas }\end{array}$} & \multicolumn{3}{|c|}{ Plântulas Anormais Deterioradas } \\
\hline & Lote 1 & Lote 2 & Médias & Lote 1 & Lote 2 & Médias & Lote 1 & Lote 2 & Médias \\
\hline AR1122 & 89Aa* & $96 \mathrm{Aa}$ & 92 & 6Abcd & $2 \mathrm{Aa}$ & 4 & 5Ade & $3 \mathrm{~A}^{\text {n.s. }}$ & 4 \\
\hline M130 & $88 \mathrm{Aa}$ & $93 \mathrm{Aa}$ & 90 & $2 \mathrm{Ad}$ & $3 \mathrm{Aa}$ & 3 & $3 \mathrm{Ae}$ & $0 \mathrm{~A}$ & 1 \\
\hline BF1358 & 84Bab & 97Aa & 91 & $2 \mathrm{Ad}$ & $2 \mathrm{Aa}$ & 2 & $2 \mathrm{Ae}$ & $0 \mathrm{~A}$ & 1 \\
\hline ZAE94 & $80 \mathrm{Bab}$ & $96 \mathrm{Aa}$ & 88 & 6Abcd & $3 \mathrm{Aa}$ & 4 & 7Acde & $1 \mathrm{~B}$ & 4 \\
\hline AR3122 & $67 \mathrm{Bcd}$ & $98 \mathrm{Aa}$ & 83 & 7Abcd & $2 \mathrm{Aa}$ & 4 & $18 \mathrm{Aab}$ & OB & 9 \\
\hline AR2112 & 66Bde & $95 \mathrm{Aa}$ & 81 & 9Abcd & $1 \mathrm{Ba}$ & 5 & $13 \mathrm{Aabc}$ & $2 \mathrm{~B}$ & 7 \\
\hline $\mathrm{Cd}$ & 62Bde & 99Aa & 81 & $15 \mathrm{Aab}$ & $1 \mathrm{Ba}$ & 8 & 8Acd & OB & 4 \\
\hline BR2113 & 62Bde & $93 \mathrm{Aa}$ & 78 & $20 \mathrm{Aa}$ & $3 \mathrm{Ba}$ & 12 & 8Acd & $1 \mathrm{~B}$ & 4 \\
\hline Controle & 58Bde & $90 \mathrm{Aa}$ & 74 & $16 \mathrm{Aab}$ & $4 \mathrm{Ba}$ & 10 & 19Aab & $5 B$ & 12 \\
\hline Testemunha & $50 \mathrm{Be}$ & 94Aa & 72 & $12 \mathrm{abc}$ & $3 \mathrm{Ba}$ & 7 & $24 \mathrm{Aa}$ & $1 \mathrm{~B}$ & 12 \\
\hline Médias & 71 & 95 & & 9 & 2 & & 10 & 1 & \\
\hline C.V.(\%) & & 4,71 & & & 41,64 & & & 38,02 & \\
\hline
\end{tabular}

*Médias seguidas por letras iguais (maiúsculas para lotes e minúsculas para procedimento de inoculação) não diferem entre si pelo teste de Tukey, a 5\% de probabilidade; n.s.não significativo.

Tabela 3 - Crescimento micelial de Fusarium sp. em placas com meio de cultivo, na presença ou ausência de diferentes

\begin{tabular}{lc}
\hline \multirow{2}{*}{ Estirpes } & Crescimento micelial $(\mathrm{cm})$ \\
\cline { 2 - 2 } Controle & Fusarium sp. \\
AR1122 & $6,4 \mathrm{a}^{*}$ \\
M130 & $5,0 \mathrm{bc}$ \\
BF1358 & $4,5 \mathrm{~cd}$ \\
ZAE94 & $4,2 \mathrm{~d}$ \\
C.V.(\%) & $5,3 \mathrm{~b}$ \\
\hline
\end{tabular}

*Médias seguidas por letras iguais não diferem entre si pelo teste de Tukey, a $5 \%$ de probabilidade.

Em relação a outras estirpes de bactérias, Tran Van et al. (2000) observaram que B. vietnamiensis TVV75 inibe o crescimento de vários fungos fitopatogênicos. Também Nandakumar et al. (2001) demonstraram que apenas uma aplicação de $P$. fluorescens na cultura do arroz induziu resistência sistêmica contra o fungo Rhizoctonia solani, impedindo o crescimento miceliano e a incidência da doença. Bacon \& Hinton (2002) observaram que estirpes de Bacillus mojavensis indicaram in vitro inibir Fusarium moniliforme. Além disso, uma das estirpes foi antagonista a muitos fungos tais como Aspergillus flavus, A. parasiticus entre outros.
Para as sementes do lote 2, que apresentavam inicialmente $94 \%$ de germinação, após um ano de armazenamento, não houve efeito dos tratamentos de inoculação na germinação e na porcentagem de plântulas anormais (deterioradas e deformadas) (Tabela 2).

Quanto ao vigor, não foi constatado efeito da inoculação com as bactérias na porcentagem de plântulas normais, na primeira contagem do teste de germinação, provenientes das sementes do lote 1 (Tabela 4). Pelo teste de classificação das plântulas em normais fortes, independentemente do lote, as sementes submetidas à inoculação com a bactéria AR3122, AR1122, BF1358, ZAE94, AR2122, CD e BR2113 apresentaram maior desenvolvimento (provavelmente massa e comprimento dos coleóptilos e raiz) e ausência de contaminação por fungos (Tabela 4). Quanto ao teste de classificação das plântulas em normais fracas, os tratamentos de inoculação com as estirpes nas sementes do lote 1 não diferiram da testemunha, exceto com a M130 (Tabela 4). Em milho, Conceição et al. (2008) também observaram que a inoculação com bactérias diazotróficas embora não tenha afetado a germinação das sementes, aumentou o desenvolvimento da parte aérea das plantas, sem promover aumento da massa de matéria seca da parte aérea, provavelmente devido à ação das bactérias sobre o alongamento celular, pela turgescência vacuolar. No entanto, Lee et al. (2006), trabalhando com bactérias 
metilotróficas do gênero Methylobacterium e entre outras bactérias diazotróficas (Enterobacter sp. e Burkholderia sp.), observaram a produção de compostos indólicos "in vitro" e a inoculação das sementes de arroz com essas bactérias favoreceu a germinação e a velocidade de germinação de sementes de arroz. Também, Biswas et al. (2000) observaram aumento do coleóptilo e da emissão de raiz primária após a inoculação de plântulas de arroz, com estirpes de Rhizobium após 120 horas de incubação a $30^{\circ} \mathrm{C}$ no escuro e aumento na velocidade de emergência das plântulas, em condições de casa de vegetação. Já, Ramamoorthy et al. (2000) após a remoção das sementes contaminadas, observaram que a inoculação com Azospirillum aumentou a germinação das sementes de arroz de dois lotes com diferentes níveis de vigor, aos 14 dias da instalação, embora isso não tenha se refletido na produção de grãos.

No segundo experimento, não houve interação entre tratamentos de inoculação e cultivares de arroz na germinação das sementes, provavelmente devido à baixa contaminação por fungos, como constatado pela porcentagem de plântulas anormais deterioradas (Tabela 5). No entanto, os tratamentos de inoculação com bactérias proporcionaram aumento de germinação já na primeira contagem do teste, com as sementes das duas cultivares com exceção da bactéria AR2112 (Tabela 6). Esse efeito também foi observado pelo teste de classificação de plântulas fortes para a bactéria BF1358, para o cultivar IR42 (Tabela 6). Quanto ao teste de classificação das plântulas fracas, os tratamentos de inoculação das sementes da cultivar IR42 não diferiram da testemunha (Tabela 6). No entanto, em sementes de Catharanthus roseus (L.), a inoculação com bactérias diazotróficas (Azospirillum e Azotobacter), isoladas da rizosfera e da raiz dessa planta, favoreceu a germinação e o vigor, em condições gnotobióticas (Karthikeyan et al., 2007). Também, em soja, foi observado que a inoculação de sementes com Methylobacterium spp. estimulou a emissão de raiz primária avaliado do $1^{\circ}$ ao $5^{\circ}$ dia das sementes devido a estímulo hormonal (Koenig et al., 2002). Novos trabalhos serão necessários para avaliar densidades populacionais de diferente bactérias, em inoculantes, na germinação de arroz.

Tabela 4 - Porcentagem de plântulas normais na primeira contagem de germinação e de plântulas normais (fortes e fracas) de dois lotes de sementes de arroz da cv. IAC 4440, inoculadas com diferentes estirpes de bactérias diazotróficas.

\begin{tabular}{|c|c|c|c|c|c|c|c|c|c|}
\hline \multirow[t]{2}{*}{ Estirpes } & \multicolumn{3}{|c|}{$\begin{array}{c}\text { Primeira Contagem de } \\
\text { Germinação }\end{array}$} & \multicolumn{3}{|c|}{ Plântulas Normais Fortes } & \multicolumn{3}{|c|}{ Plântulas Normais Fracas } \\
\hline & Lote 1 & Lote 2 & Médias & Lote 1 & Lote 2 & Médias & Lote 1 & Lote 2 & Médias \\
\hline AR1122 & $19 B^{*}$ & 31Abcd & 25 & 30 & 52 & $41 \mathrm{abc}$ & 56Aab & 43Aab & 49 \\
\hline M130 & $17 \mathrm{~A}$ & $21 \mathrm{Ac}$ & 19 & 27 & 48 & $38 \mathrm{bc}$ & $60 \mathrm{Aa}$ & 43Bab & 51 \\
\hline BF1358 & $21 \mathrm{~A}$ & $23 \mathrm{Abc}$ & 22 & 33 & 50 & $42 \mathrm{abc}$ & 46Aab & 42Aab & 44 \\
\hline ZAE94 & $26 B$ & 37Aabc & 31 & 38 & 65 & $52 \mathrm{ab}$ & 43Aab & 35Aab & 39 \\
\hline AR3122 & $27 \mathrm{~A}$ & 30Aabc & 29 & 38 & 67 & $53^{\mathrm{a}}$ & $30 \mathrm{Ab}$ & $26 \mathrm{Ab}$ & 28 \\
\hline AR2112 & $27 \mathrm{~A}$ & 34Aabc & 30 & 29 & 50 & $40 \mathrm{abc}$ & 40Aab & 46Aa & 43 \\
\hline $\mathrm{Cd}$ & $20 \mathrm{~A}$ & $25 \mathrm{Abc}$ & 22 & 28 & 52 & $40 \mathrm{abc}$ & $32 \mathrm{Aab}$ & 43Aab & 37 \\
\hline BR2113 & 19B & $35 \mathrm{Aabc}$ & 27 & 25 & 60 & $42 \mathrm{abc}$ & 38Aab & 34Aab & 34 \\
\hline Controle & $22 \mathrm{~A}$ & 29Aabc & 26 & 25 & 43 & $34 \mathrm{c}$ & $34 \mathrm{Bb}$ & 47Aa & 40 \\
\hline Testemunha & 19B & $43 \mathrm{Aa}$ & 31 & 23 & 58 & $40 \mathrm{abc}$ & $28 \mathrm{Ab}$ & 37Aab & 32 \\
\hline Médias & 21 & 31 & & $29 B$ & $55 \mathrm{~A}$ & & 40 & 39 & \\
\hline C.V. $(\%)$ & & 12,23 & & & 10,36 & & & 11,21 & \\
\hline
\end{tabular}

*Médias seguidas por letras iguais (maiúsculas para lotes e minúsculas para procedimento de inoculação) não diferem entre si pelo teste de Tukey, a 5\% de probabilidade. 
Tabela 5 - Porcentagem de germinação e de plântulas deformadas e deterioradas de dois lotes de sementes das duas cultivares de arroz IR42 (C1) e Zebu Branco (C2) inoculadas com diferentes estirpes de bactérias diazotróficas.

\begin{tabular}{|c|c|c|c|c|c|c|c|c|c|}
\hline \multirow{2}{*}{ Estirpes } & \multicolumn{3}{|c|}{ Germinação } & \multicolumn{3}{|c|}{ Plântulas Anormais Deformadas } & \multicolumn{3}{|c|}{ Plântulas Anormais Deterioradas } \\
\hline & $\mathrm{C} 1$ & $\mathrm{C} 2$ & Medias & $\mathrm{C} 1$ & $\mathrm{C} 2$ & Médias & $\mathrm{C} 1$ & $\mathrm{C} 2$ & Médias \\
\hline BF1358 & 99 & 93 & $96 *$ n.s & 0 & 3 & $2 \mathrm{a}$ & 0 & 3 & $2^{\mathrm{n} . \mathrm{s}}$ \\
\hline AR3122 & 97 & 95 & 96 & 2 & 4 & $3 a$ & 0 & 3 & 2 \\
\hline AR1122 & 96 & 89 & 93 & 2 & 7 & $5 \mathrm{ab}$ & 0 & 0 & 0 \\
\hline ZAE94 & 93 & 88 & 91 & 7 & 8 & $8 \mathrm{ab}$ & 0 & 1 & 1 \\
\hline M130 & 91 & 92 & 92 & 8 & 6 & $7 \mathrm{ab}$ & 0 & 0 & 0 \\
\hline AR2112 & 90 & 91 & 91 & 6 & 6 & $6 a b$ & 1 & 1 & 1 \\
\hline Controle & 95 & 86 & 91 & 4 & 11 & $8 \mathrm{ab}$ & 3 & 3 & 3 \\
\hline Testemunha & 93 & 88 & 91 & 4 & 9 & $7 \mathrm{ab}$ & 0 & 4 & 2 \\
\hline Médias & 94 & 90 & & $4 \mathrm{~B}$ & $7 \mathrm{~A}$ & & $1 \mathrm{~A}$ & $2 \mathrm{~A}$ & \\
\hline C.V.(\%) & \multicolumn{3}{|c|}{2,84} & \multicolumn{3}{|c|}{45,23} & \multicolumn{3}{|c|}{60,86} \\
\hline
\end{tabular}

*Médias seguidas por letras iguais (maiúsculas para cultivares e minúsculas para procedimento de inoculação) não diferem entre si pelo teste de Tukey, a $5 \%$ de probabilidade. ${ }^{\text {n.s. }}$ não significativo.

Tabela 6 - Porcentagem de plântulas normais na primeira contagem de germinação e de plântulas normais (fortes e fracas) de dois lotes de sementes das duas de arroz IR42 (C1) e Zebu Branco (C2), inoculadas com diferentes estirpes de bactérias diazotróficas.

\begin{tabular}{|c|c|c|c|c|c|c|c|c|c|}
\hline \multirow{2}{*}{ Estirpes } & \multicolumn{3}{|c|}{ Primeira Contagem de Germinação } & \multicolumn{3}{|c|}{ Plântulas Normais Fortes } & \multicolumn{3}{|c|}{ Plântulas Normais Fracas } \\
\hline & $\mathrm{C} 1$ & $\mathrm{C} 2$ & Medias & $\mathrm{C} 1$ & $\mathrm{C} 2$ & Médias & $\mathrm{C} 1$ & $\mathrm{C} 2$ & Médias \\
\hline BF1358 & $60 \mathrm{Aa}^{*}$ & $51 \mathrm{Aa}$ & 56 & $74 \mathrm{Aa}$ & $59 \mathrm{Ba}$ & 67 & $25 \mathrm{Ab}$ & $34 \mathrm{~A}^{\mathrm{n} . \mathrm{s}}$ & 30 \\
\hline AR3122 & 57Aab & 46Аa & 52 & 1Aabc & $57 \mathrm{Aa}$ & 59 & $36 \mathrm{Abc}$ & $38 \mathrm{~A}$ & 37 \\
\hline AR1122 & $43 \mathrm{Abc}$ & $51 \mathrm{Aa}$ & 47 & $1 \mathrm{Abcd}$ & $53 \mathrm{Aab}$ & 52 & 45Aab & $35 \mathrm{~A}$ & 40 \\
\hline ZAE94 & $56 \mathrm{Aab}$ & $50 \mathrm{Aa}$ & 53 & $62 \mathrm{Aab}$ & $56 \mathrm{Aa}$ & 59 & $31 \mathrm{Abc}$ & $32 \mathrm{~A}$ & 32 \\
\hline M130 & $53 \mathrm{Aab}$ & 48Aa & 50 & 7Aabc & $52 \mathrm{Aab}$ & 55 & $34 \mathrm{Abc}$ & $40 \mathrm{~A}$ & 37 \\
\hline AR2112 & $40 \mathrm{Abc}$ & 37Aab & 39 & 62Aab & 47Bab & 55 & $26 \mathrm{Bb}$ & $44 \mathrm{~A}$ & 36 \\
\hline Controle & 29Ad & 36Aab & 33 & $42 \mathrm{Ad}$ & 44Aab & 43 & $53 \mathrm{Aa}$ & $42 \mathrm{~A}$ & 47 \\
\hline Testemunha & $32 \mathrm{Ad}$ & $27 \mathrm{Ab}$ & 29 & 46Acd & $40 \mathrm{Ab}$ & 43 & 47Aab & $48 \mathrm{~A}$ & 48 \\
\hline Médias & 45 & 44 & & 56 & 51 & & 37 & 39 & \\
\hline C.V.(\%) & & 8,22 & & & 6,68 & & & 9,91 & \\
\hline
\end{tabular}

*Médias seguidas por letras iguais (maiúsculas para cultivares e minúsculas para procedimento de inoculação) não diferem entre si pelo teste de Tukey, a 5\% de probabilidade. ${ }^{\text {n.s. }}$ não significativo.

\section{CONCLUSÕES}

As bactérias AR1122, M130, BF1358, ZAE94 e AR3112 podem ser selecionadas para formular inoculante para sementes de arroz.

A inoculação com as bactérias diazotróficas aumenta a velocidade de germinação das sementes dos cultivares IR42 e Zebu Branco, com menor contaminação por fungos.

As estirpes BF1358, M130, AR1122 e ZAE94 apresentam efeito antagônico ao fungo Fusarium sp., isolado de sementes de arroz.

\section{REFERÊNCIAS BIBLIOGRÁFICAS}

ARAÚJO, A.E.S. Caracterização e uso de bactérias diazotróficas isoladas de diferentes cultivares de Arroz originárias do estado do maranhão. 2008. 88f. Tese (Doutorado em Fitotecnia)-Universidade Federal Rural do Rio de Janeiro, Seropédica, 2008.

ARSEGO, O.; BAUDET, L.; AMARAL, A.S.; HÖLBIG, L.; PESKE, F. Recobrimento de sementes de arroz irrigado com ácido giberélico, fungicidas e polímero. Revista Brasileira de Sementes, Brasília, v.28, p.201-206, 2006. 
BACON, C.W.; HINTON, D.M. Endophytic and biological control potential of Bacillus mojavensis and related species. Biological Control, Oxford, v.23, p.274284, 2002.

BALDANI, V.L.D. Efeito da inoculação de Herbaspirillum spp. no processo de colonização e infecção de plantas de arroz e ocorrência e caracterização parcial de uma nova bactéria diazotrófica. 1996. 262f. Tese (Doutorado em Agronomia)-Universidade Federal Rural do Rio de Janeiro, Seropédica, 1996.

BARAZANI, O.; FRIEDMAN, J. IS IAA the major root growth factor secreted from plant-growth-mediating bacteria? Journal of Chemical Ecology, New York, v.25, p.2397-2406, 1999.

BEVIVINO, A.; PEGGION, V.; CHIARINI, L.; TABACCHIONI, S.; CANTALE, C.; DALMASTRI, C. Effect of Fusarium verticillioides on maize-rootassociated Burkholderia cenocepacia populations. Research in Microbiology, Paris, v.156, p.974-983, 2005.

BEVIVINO, A.; SARROCCO, S.; DALMASTRI, C.; TABACCHIONI, S.; CANTALE, C.; CHIARINI, L. Characterization of a free-living maize-rhizosphere population of Burkholderia cepacia: effect of seed treatment on disease suppression and growth promotion of maize. FEMS Microbiology Ecology, Amsterdam, v.27, p.225-237, 1998.

BISWAS, J.C.; LADHA, J.K.; DAZZO, F.B.; YANNI, Y.G.; ROLFE, B.G. Rhizobial inoculation influences seedling vigor and yield of rice. Agronomy Journal, Madison, v.92, p.880-886, 2000.

BRASIL. Ministério da Agricultura e Reforma Agrária. Regras para análise de sementes. Brasília, 1992. 365p.

CAVAGLIERI, L.; ORLANDOA, J.; RODRÍGUEZ, M.I.; CHULZEB, S.; ETCHEVERRY, M. Biocontrol of Bacillus subtilis against Fusarium verticillioides in vitro and at the maize root level. Research in Microbiology, Paris, v.156, p.748-754, 2005.

CHUN, S.C.; SCHNEIDER, R.W.; COHN, M.A. Sodium hypochlorite: effect of solution $\mathrm{pH}$ on rice seed disinfestation and its direct effect on seedling growth. Plant Disease, Saint Paul, v.81, p.821-824, 1997.
CONCEIÇÃO, P.M.; VIEIRA, H.D.; CANELLAS, L.P.; MARQUES JUNIOR, R.B.; OLIVARES, F.L. Recobrimento de sementes de milho com ácidos húmicos e bactérias diazotróficas endofíticas. Pesquisa Agropecuária Brasileira, Brasília, v.43, n.4, p.545-548, 2008.

ELBELTAGY, A.; NISHIOKI, K.; SATO, T.; SUZUKI, H.Y.B.; HAMADA, T.; ISAWA, T.; MITSUI, H.; MINAMISAWA, K. Endophytic colonization and in planta nitrogen fixation by a Herbaspirillum sp. isolated from wild rice species. Applied and Environmental Microbiology, Washington, v.67, p.5285-5293, 2001.

FAROOQ, M.; BARSA, S.M.A.; WAHID, A. Priming of field-sown rice seed enhances germination, seedling establishment, allometry and yield. Plant Growth Regulator, Dordrecht, v.49, p.285-294, 2006.

GOMES, E.P. Curso de estatística experimental. Piracicaba: FEALQ. 1990. 404p.

HAN, J.; SUN, L.; DONG, X.; CAI, Z.; YANG, H.; WANG, Y.; SONG, W. Characterization of a novel plant growthpromoting bacteria strain Delftia tsuruhatensis HR4 both as a diazotroph and a potential biocontrol agent against various pathogens. Systematic and Applied Microbiology, Stuttgart, v.28, p.66-76, 2005.

KARTHIKEYAN, B.; JALEEL, C.A.; GOPI, R.; DEIVEEKASUNDARAM, M. Alterations in seedling vigour and antioxidant enzyme activities in Catharanthus roseus under seed priming with native diazotrophs. Journal of Zhejiang University, Tamil Nadu, v.8, p.453-457, 2007.

KIM, H.; NISHIYAMA, M.; KUNITO, T.; SENOO, K.; KAWAHARA, K.; MURAKAMI, K.; OYAIZU, H. High population of Sphingomonas species on plant surface. Journal of Applied Microbiology, Stuttgart, v.85, p.731736, 1998.

KOENIG, R.L.; MORRIS, R.O.; POLACCO, J.C. tRNA is the source of low-level trans-zeatin production in Methylobacterium spp. Applied and Environmental Microbiology, Washington, v.184, p.1832-1842, 2002.

LEE, H.S.; MADHAIYAN, M.; KIM, C.W.; CHOI, S.J.; CHUNG, K.Y. Physiological enhancement of early growth of rice seedlings (Oryza sativa L.) by production of phytohormone of N2-fixing methylotrophic isolates. Biology and Fertility of Soils, Berlin, v.42, p.402-408, 2006. 
MELO, I.S.; VALARINE, P.J. Potencial de rizobactérias no controle de Fusarium solani (Mart.) Sacc. em pepino (Cucumis sativum L.). Scientia Agricola, Piracicaba, v.52, p.326-330, 1995.

MUTHUKUMARASAMY, R.; KANG, U.G.; PARK, K.D.; JEON, W.T.; CHO, Y.S.; KWON, S.W.; SONG, J.; ROH, D.H.; REVATHI, G. Enumeration, isolation and identification of diazotrophs from Korean wetland rice varieties grown with long-term application of $\mathrm{N}$ and compost and their short-term inoculation effect on rice plants. Journal of Applied Microbiology, Stuttgart, v.102, p.981-991, 2007.

NAKAGAWA, J. Testes de vigor baseado no desempenho das plântulas. In: KRZYZANOWSKI, F.C.; VIEIRA, R.D.; FRANÇA NETO, J.B. Vigor de sementes: conceitos e testes. Londrina: Abrates, 1999. p.1-24.

NANDAKUMAR, R.; BABU, S.; VISWANATHAN, R.; RAGUCHANDER, T.; SAMIYAPPAN, R. Induction of systemic resistance in rice against sheath blight disease by Pseudomonas fluorescens. Soil Biology Biochemestry, Elmsford, v.33, p.603-612, 2001.

PENG, S.; BISWAS, J.C.; LADHA, J.K. Influence of rhizobial inoculation on photosynthesis and grain yield of rice. Agronomy Journal, Madison, v.94, p.925-929, 2002.

RAMAMOORTHY, K.; NATARAJAN, N.; KILLIKULAM, T.N.A.U.; VALLANAD, P.O. Seed biofortification with Azospirillum spp. for improvement of seedling vigour and productivity in rice (Oryza sativa L.). Seed Science and Technology, Zurich, v.28, p.809815,2000 .

RAVEN, P.H.; EVERT, R.F.; EICHHORN, S. Regulando o crescimento e o desenvolvimento: os hormônios vegetais. In: RAVEN, P.H. Biologia vegetal. Tradução de Jane Elizabeth Kraus. 6.ed. Rio de Janeiro: Guanabara Koogan, 2001. p.649-675.

RODRIGUES NETO, J.; MALAVOLTA JUNIOR, V.A.; VICTOR, O. Meio simples para isolamento e cultivo de Xanthomonas campestris pv. Citri Tipo B. Summa Phytopatologica, Botucatu, v.12, p.16, 1986.

RODRIGUEZ, H.; FRAGA, R. Phosphate solubilizing bacteria and their role in plant growth promotion. Biotechnology Advances, New York, v.17, p.319-339, 1999.

TRAN VAN, V.; BERGE, O.; KE, S.N.; BALANDREAU, J.; HEULIN, T. Repeated beneficial effects of rice inoculation with a strain of Burkholderia vietnamiensis on early and late yield components in low fertility sulphate acid soils of Vietnã. Plant and Soil, The Hague, v.218, p.273-284, 2000.

WEBER, O.B.; MUNIZ, C.R.; VITOR, A.O.; FREIRE, F.C.O.; OLIVEIRA, V.M. Interation of endophytic diazotrofic baxteria and Fusarium oxysporum f.sp. cubense on plantlets of banana 'Maça". Plant Soil, The Hague, v.298, p.47-56, 2007. 